\title{
Whitening of polyvinyl alcohol used as restoration material for Shohekiga
}

\author{
Yusuke Okada $^{1}$, Wataru Kawanobe ${ }^{2}$, Noriko Hayakawa ${ }^{2}$, Sachiko Tsubokura ${ }^{2}$, Riichiro Chujo ${ }^{3}$, \\ Hitoshi Fujimatsu ${ }^{4}$, Tokihiro Takizawa ${ }^{4}$ and Toshihiro Hirai ${ }^{4}$
}

Polyvinyl alcohol (PVA) has been used to prevent flaking of paint pigments on traditional Japanese Shohekiga painted screens and panels. However, over time these PVA coatings whiten. To date, the mechanism of this whitening has not been studied from the point of view of polymer degradation. In this study, a piece of whitened PVA was obtained from a painted wooden panel. The PVA whitening mechanism was studied in this piece using scanning electron microscopy (SEM) and functional group analysis by Fourier transform-infrared spectroscopy (FT-IR) and X-ray photoelectron spectroscopy (XPS). SEM showed that the surface of the whitened PVA thin film was irregular and rugged, and many micrometer-sized cracks were observed. This suggests that efficient scattering of all visible light from the cracks causes whitening. FT-IR and XPS measurements revealed that inter- and intra-chain dehydration and chemical crosslinking ( $\mathrm{C}-\mathrm{O}$ ether linkage) occur on the surface of the whitened PVA.

Polymer Journal (2011) 43, 74-77; doi:10.1038/pj.2010.103; published online 3 November 2010

Keywords: cultural property; degradation; polyvinyl alcohol; restoration material; Shohekiga; whitening

\section{INTRODUCTION}

Polyvinyl alcohol (PVA) is a common commercial polymer. Along with other synthetic polymers, it has been applied to the conservation of paintings for cultural heritage purposes. The first instance of the use of a polymeric material for restoration involved an acrylic resin in the Ryosenji temple in Nara city (Japan) in $1942 . .^{1-4}$ Since then, synthetic polymers have become increasingly popular for the restoration of Japanese cultural property. These materials work particularly well for restoring items that have been poorly preserved and cannot be restored with traditional techniques. They also make up for a lack of skilled conservators, because it is possible to easily handle them further than traditional materials. PVA was believed to be stable and to provide good adhesion and ease of handling. Consequently, it was used for the prevention of pigment flaking in Japanese Shohekiga screen and panel paintings. However, over time the PVA coatings on these paints have begun to whiten. ${ }^{5,6}$ To date, the mechanism of this whitening has not been investigated from the point of view of polymer degradation. Whitened PVA cannot be removed from screen and panel paints easily because it is water insoluble. This is a serious issue in the field of painting conservation, and despite many efforts, no effective method for remediation has been found. ${ }^{7,8}$

Our ultimate goal is to find a method for the safe removal of whitened PVA from the surface of valuable paintings. As a first step in achieving this, we studied the mechanism by which PVA whitening occurs. A piece of whitened PVA was removed from a wooden panel painting, but we were limited to certain analyses because it was very thin and small.

The surface was observed using scanning electron microscopy (SEM). Functional group analysis was conducted by Fourier transform-infrared spectroscopy (FT-IR) and X-ray photoelectron spectroscopy (XPS). The results were compared with those from reference samples.

We also report some experimental facts involved with whitening revealed by the results.

\section{EXPERIMENTAL PROCEDURE}

Materials

Whitened PVA sample. A thin film PVA sample (PU1) was removed from the surface of a 17th century Japanese panel painting. The sample was $2 \mathrm{~mm} \times 3 \mathrm{~mm}$ in size and about $30-\mu \mathrm{m}$ thick.

Reference samples. Four reference PVA samples (RA1-RA4) were used for comparison of spectroscopic data with PU1. PVA powders (Table 1; Kuraray, Tokyo, Japan) were used to prepare PVA films (50-100 $\mu \mathrm{m}$ thickness) by solvent casting as follows: PVA powder was dissolved in distilled water by stirring with a magnetic stirrer at $80^{\circ} \mathrm{C}$. The aqueous solution was poured into a polystyrene Petri dish at room temperature and then dried for at least 2 days in an oven at $30^{\circ} \mathrm{C}$. After drying, the PVA film was pealed from the Petri dish.

Poly(methyl methacrylate) (PMMA) sample. PMMA powder (Sigma-Aldrich, St Louis, MO, USA, $\left.M_{\mathrm{w}}=120000\right)$ was dissolved in toluene and then formed into a film on a glass plate using spin coating. The FT-IR spectra of the PMMA

${ }^{1}$ Department of Bioscience and Textile Technology, Interdisciplinary Graduate School of Science and Technology, Shinshu University, Ueda-shi, Nagano, Japan; ${ }^{2}$ The Center for Conservation Science and Restoration Techniques, National Research Institute for Cultural Properties, Taito-ku, Tokyo, Japan; ${ }^{3}$ The Center for Conservation Science and Restoration Techniques, National Research Institute for Cultural Properties, Machida-shi, Tokyo, Japan and ${ }^{4}$ Faculty of Textile and Science, Shinshu University, Nagano, Japan

Correspondence: Y Okada, Department of Bioscience and Textile Technology, Interdisciplinary Graduate School of Science and Technology, Shinshu University, 3-15-1 Tokida, Ueda-shi, Nagano 386-8567, Japan.

E-mail: s09t102@shinshu-u.ac.jp

Received 17 March 2010; revised 13 September 2010; accepted 15 September 2010; published online 3 November 2010 
Table 1 Properties of reference PVA samples

\begin{tabular}{llcc}
\hline Sample name & Grade & Polymerization degree & Saponification degree/\% \\
\hline RA1 & PVA-117 & 1700 & $98-99$ \\
RA2 & PVA-217 & 1700 & $87-89$ \\
RA3 & PVA-105 & 500 & $98-99$ \\
RA4 & PVA-205 & 500 & $87-89$ \\
\hline
\end{tabular}

Abbreviation: PVA, polyvinyl alcohol.

film were obtained by using the attenuated total reflection (ATR) method to be compared with those of the PVA films.

\section{Measurements}

SEM observation. SEM (Hitachi High-Tech Instruments S-3000) observation of PU1 was used to investigate the relationship between whitening and surface structure. SEM observations of the PVA samples were carried out without metal coating. The voltage and current settings were $20 \mathrm{kV}$ and $30 \mu \mathrm{A}$, respectively.

FT-IR-ATR measurement. FT-IR was carried out to analyze functional groups on the surface of PU1 and verify changes in chemical structure during PVA degradation. Reflective IR spectra of the samples were obtained using the ATR method. FT-IR-ATR measurements were carried out in air using a Shimadzu Corporation IR Prestige-21 FT-IR spectrometer (Shimadzu, Kyoto, Japan) with a Smiths Detection DuraSample IR II ATR attachment. Spectra were obtained as the average of 100 scans at $4-\mathrm{cm}^{-1}$ resolution. ATR correction was performed with IR solution software (Shimadzu). Absorption peaks assigned to $\mathrm{CO}_{2}$ and water vapor were removed from the spectra. After a zero baseline correction, the spectra were normalized against the $v_{\mathrm{CH} 2}$ peak at $2935 \mathrm{~cm}^{-1}$, which was less variable than other peaks and, therefore, may remain constant in the degradation process.

XPS measurement. Wide scan spectra measurement: Impure substances on the surface of PU1 were detected with XPS wide scan spectra using KRATOS AXISUltra (KRATOS, Manchester, UK) with $\mathrm{MgK}_{\alpha}$ radiation. A whitened PVA sample was fixed on the sampling stage using carbon tape. An electron beam gun was used to neutralize the sample charge. Survey scans were collected from 1100 to $0 \mathrm{eV}$ with a step width of $1 \mathrm{eV}$ and pass energy detection of $160 \mathrm{meV}$.

$C_{I s}$ spectra measurement: Changes in the chemical structure of PVA due to degradation were verified with $\mathrm{C}_{1 \mathrm{~s}}$ spectra obtained from the surface of PU1 by XPS. XPS was performed using KRATOS AXIS-Ultra with $\mathrm{MgK}_{\alpha}$ radiation. The whitened PVA sample and reference PVA samples were fixed on the sampling stage using carbon tape. An electron beam gun was used to neutralize the sample charge. Survey scans were collected from $300-275 \mathrm{eV}$ with a step width of $0.1 \mathrm{eV}$ and pass energy detection of $160 \mathrm{meV}$. The $\mathrm{C}_{1 \mathrm{~s}}$ binding energy in $\mathrm{CH}_{2}$ species was set to $285.0 \mathrm{eV}$. Deconvolution for $\mathrm{C}_{1 \mathrm{~s}}$ was performed using Gaussian-Lorentzian line shapes.

\section{RESULTS AND DISCUSSION}

\section{SEM observation}

SEM micrographs of PU1 (Figure 1) showed that the surface features were irregular, rugged and on the scale of several hundred micrometers. Many micrometer-sized wrinkles and, especially, cracks were also observed along with pigments and dust. It has been shown that whitened PVA becomes transparent when it is coated in water. ${ }^{6}$ This suggests that cracks in the PVA surface cause the whitening. Light scattering from the surface of a material is known to occur when the refractive indices are different for materials on either side of an interface. The light scattering intensity is also dependent on the magnitude of the refractive indices and size of the scattering material. The refractive index difference for PVA and air is large when the air is enclosed in a crack in PVA. This enhances the light scattering intensity. However, if the air is replaced with water, the scattering intensity becomes less intense because the refractive index difference for water and PVA is small. In this case, the difference between the refractive
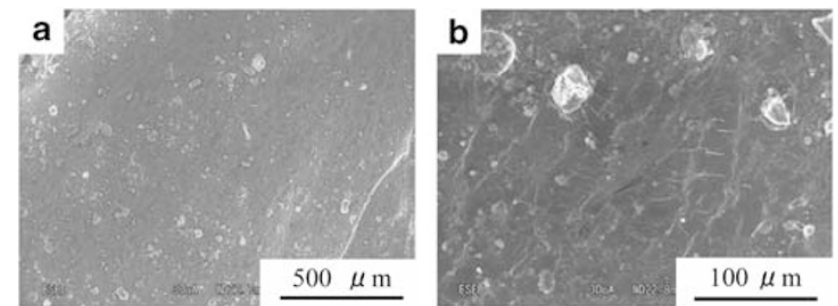

Figure 1 Scanning electron microscopy images of PU1: (a) magnified 80 times and (b) magnified 450 times.

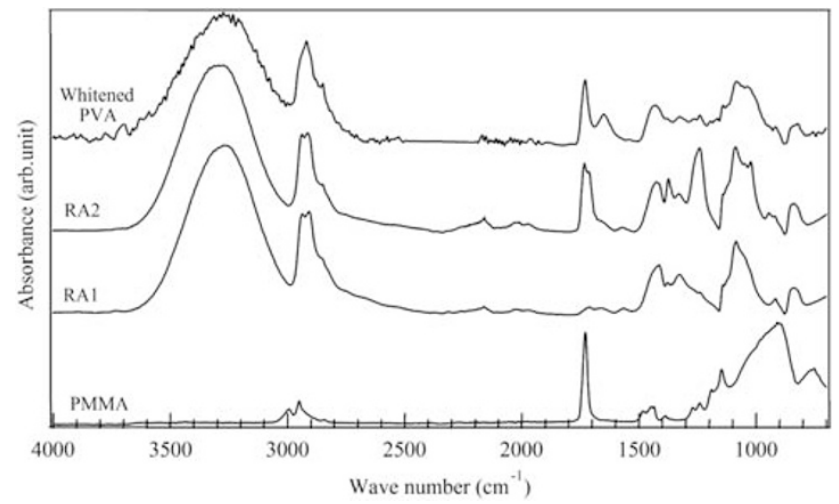

Figure 2 Fourier transform-infrared spectroscopy-attenuated total reflection spectra of PU1 and reference samples. PMMA, poly(methyl methacrylate); PVA, polyvinyl alcohol.

Table 2 Assignment of the FT-IR-ATR characterization of the PVA samples

\begin{tabular}{ll} 
Wave number $\left(\mathrm{cm}^{-1}\right)$ & Assignments \\
\hline 1040 & $v(\mathrm{C}-\mathrm{O})$ in acetyl group? \\
1090 & $v(\mathrm{C}-\mathrm{O})^{10-13}$ \\
1170 & $v(\mathrm{C}-\mathrm{O}-\mathrm{C})$ in ether group? ${ }^{13}$ \\
1245 & $v_{\mathrm{s}}(\mathrm{C}-\mathrm{O}-\mathrm{C})$ in acetyl group? \\
1265 & $v_{\mathrm{a}}(\mathrm{C}-\mathrm{C}-\mathrm{O})$ in PMMA? \\
1320 & $\delta(\mathrm{CH}+\mathrm{OH})^{10,12}$ \\
1380 & $\omega(\mathrm{CH})^{12}$ \\
1420 & $\delta(\mathrm{CH})^{10,13}$ \\
1650 & $v(\mathrm{C}=\mathrm{C})^{15,16}$ \\
1730 & $v(\mathrm{C}=0)^{10,11,17}$ \\
2850 & $v(\mathrm{CH})^{12}$ \\
$2900-2950$ & $v(\mathrm{CH})^{10-12,17}$ \\
$3000-3500$ & $v(\mathrm{O}-\mathrm{H})^{10,12,13}$ \\
\hline
\end{tabular}

Abbreviations: $\delta$, bending; $v$, stretching; $\omega$, wagging; a, asymmetric; FT-IR-ATR, Fourier transform-infrared spectroscopy-attenuated total reflection; PVA, polyvinyl alcohol; s, symmetric.

indices at the water-PVA interface decreases as the PVA swells because of the water. This means that less light will be scattered as time progresses. The micrometer-sized cracks in PU1 can efficiently scatter all visible light because their size is slightly larger than the wavelength of visible light.

\section{FT-IR-ATR measurement}

The FT-IR-ATR spectra of PU1 and PVA reference films are shown in Figure 2. Peak assignments are listed in Table 2. ${ }^{9-15,17}$ PU1 was obtained from a painted wooden panel that had been restored in the 1950s, first with PVA to improve paint adhesion and then with acrylate resin (that is, PMMA) on top of the PVA layer to improve 
water resistance. ${ }^{2}$ The acrylate resin was removed using organic solvents when re-restoration was carried out at a later date.

The spectrum of PU1 (Figure 2) shows small peaks at 1245, 1265 and $1380 \mathrm{~cm}^{-1}$. These can be attributed to the acetyl groups in the unsaponificated PVA polymer chain or in acrylate resin (PMMA), which may have remained on the surface after the re-restoration.

The absorption at $1730 \mathrm{~cm}^{-1}$ was assigned to a $\mathrm{C}=\mathrm{O}$ stretching vibration and could be attributed to the carbonyl group in acrylate resin, which is formed by the degradation of PVA. The absorption at $3000-3500 \mathrm{~cm}^{-1}$ corresponds to the $\mathrm{O}-\mathrm{H}$ stretching vibration and hydrogen bonds, whereas that at $1320 \mathrm{~cm}^{-1}$ corresponds to $\mathrm{C}-\mathrm{H}$ and $\mathrm{O}-\mathrm{H}$ bending vibrations. Both of these peaks were smaller than those in the reference samples, which implies that interchain dehydration occurs in the PVA obtained from the painted wooden panel. The peaks at 1040 and $1170 \mathrm{~cm}^{-1}$ may be attributed to the $\mathrm{C}-\mathrm{O}$ ether bond of the PVA polymer chain. The strong absorption at $1650 \mathrm{~cm}^{-1}$ could be assigned to the $\mathrm{C}=\mathrm{C}$ stretching vibration. It is known that $\mathrm{C}=\mathrm{C}$ bonds are formed by intrachain dehydration during thermal and photodegradation. ${ }^{10,16}$

Akhter et al. ${ }^{13}$ reported that PVA degrades through the routes depicted in Figure 3, and dehydration and crosslinking may occur in PVA chains. ${ }^{13,16}$ The aforementioned PU1 peaks are consistent with the result by Akhter et al.; thus, three-dimensional chemical networks associated with dehydration and crosslinking can be formed on the PU1 surface, and curing of the surface occurs simultaneously. It is known among conservators of Shohekiga that whitened PVA becomes insoluble in water; therefore, our guess coincides with this fact.

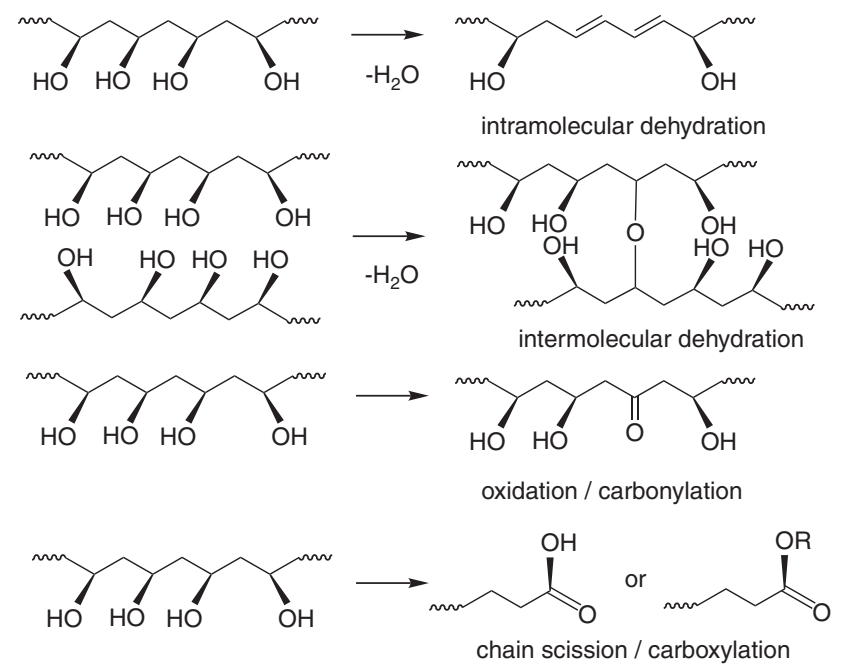

Figure 3 Schematic diagram of polyvinyl alcohol degradation routes.
On the other hand, animal glue has been used as a traditional binder of pigments in Japanese paintings. The elasticity of animal glue can vary significantly by changes in humidity. ${ }^{18}$ PVA was coated on a color layer that contains animal glue. Hence, we hypothesize that wrinkles and cracks can be formed on the PVA surface easily by the difference in elastic properties between cured PVA and animal glue on the color layer. As a result, cracks on the PVA surface can cause whitening as described above.

\section{XPS measurement}

Wide scan spectra measurement. A wide scan spectrum was obtained of the surface of PU1 (Figure 4) and partially magnified (Figure 5). The peaks in Figures 4 and 5 could be assigned to calcium, sulfate and silicon electron orbitals. These elements may be contained in the pigments and dust observed on the surface of the PVA by SEM. The appearance of calcium indicates the existence of $\mathrm{CaCO}_{3}$, which is widely used as a white pigment in Japanese paintings.

$C_{1 s}$ spectra measurement. Figure 6 shows the $\mathrm{C}_{1 \mathrm{~s}}$ spectra of PU1 and reference PVA films (RA1 and RA2). A small peak at $289.1 \mathrm{eV}$ in the spectrum of RA2 could be ascribed to acetyl groups in the unsaponificated PVA chain. ${ }^{11,12,19}$ The lack of a clear peak at $289.1 \mathrm{eV}$ in the spectrum of PU1 indicates that it has a higher degree of saponification than RA2. However, the $\mathrm{C}_{1 \mathrm{~s}}$ band of PU1 at around $287-288 \mathrm{eV}$ was more intense than in the reference PVA samples. These peaks are assigned to carbonyl or formyl groups, and this suggests degradation of PU1. On the other hand, dehydration proceeds on PU1 because the $\mathrm{C}-\mathrm{OH}$ peak at $286.5 \mathrm{eV}$ in the spectrum is smaller than those of RA1 and RA2. Finally, the $\mathrm{C}-\mathrm{O}-\mathrm{C}$ peak at $285.8 \mathrm{eV}$ appears in the spectrum of PU1, which indicates chemical crosslinking of PVA chains. These results are in good accord with FT-IR-ATR measurements.

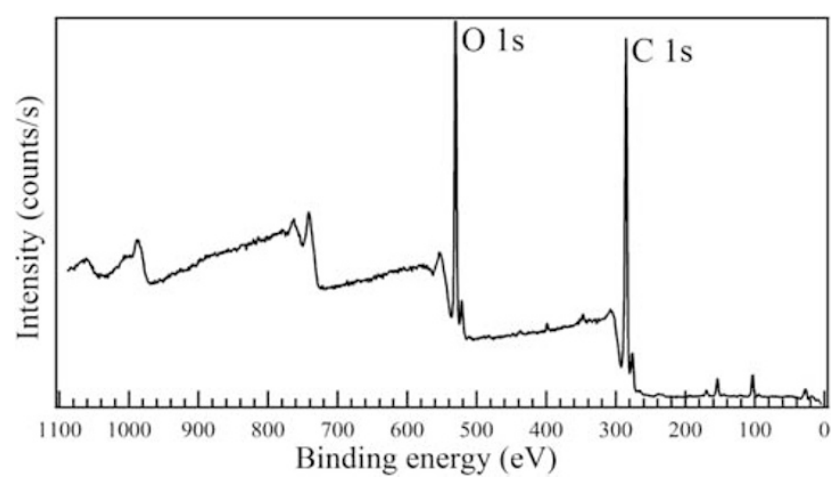

Figure $4 \mathrm{X}$-ray photoelectron spectroscopy wide scan spectrum of PU1 $(0-1100 \mathrm{eV})$.
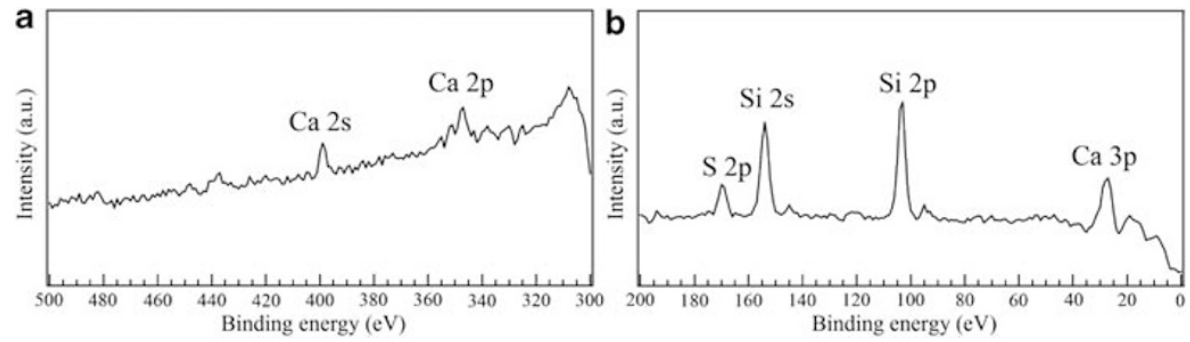

Figure 5 X-ray photoelectron spectroscopy wide scan spectra of PU1 at (a) $300-500 \mathrm{eV}$ and at (b) 0-200 eV. 


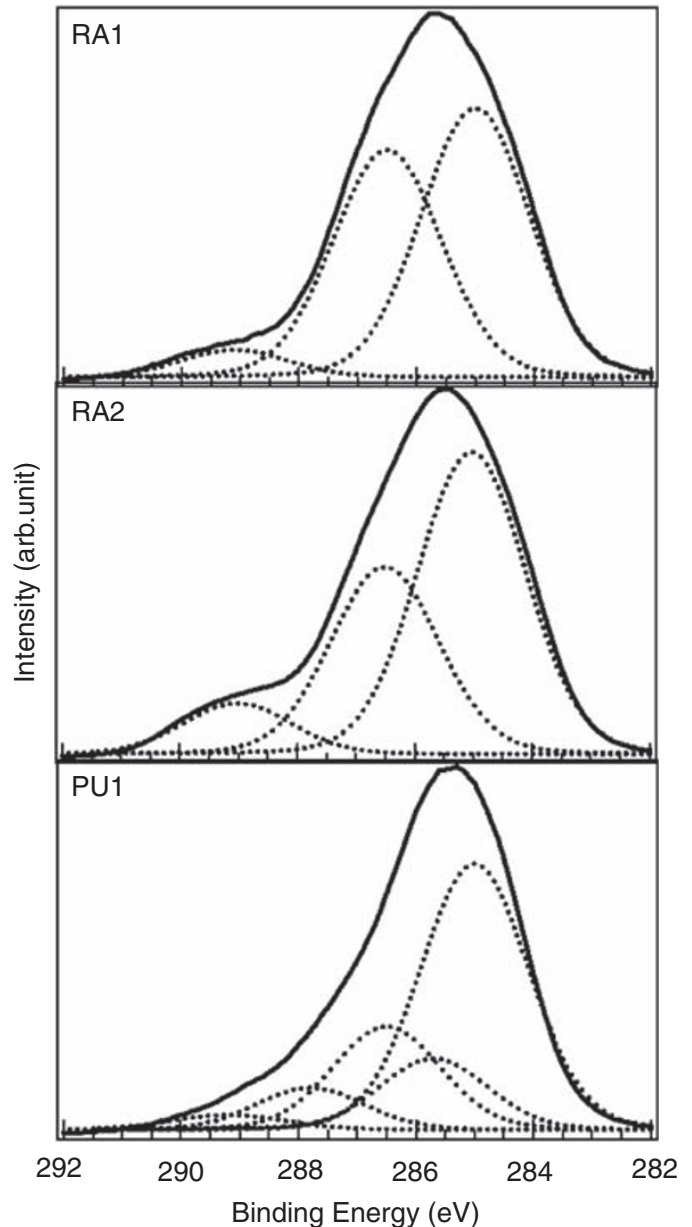

Figure 6 X-ray photoelectron spectroscopy $\mathrm{C}_{1 \mathrm{~s}}$ spectra of PU1 and reference samples.

\section{Conclusions}

A piece of PVA that had been used in the restoration of a historic Japanese painted wooden panel was obtained for analysis. SEM observation and functional group analysis by FT-IR and XPS were used to study the mechanism that caused whitening of this PVA piece. SEM showed that the surface of the whitened PVA thin film was irregular and rugged on the scale of several hundred micrometers and covered with many micrometer-sized cracks, pigments and dust. The whitening seemed to be caused by the scattering of all visible light by the cracks in the PVA. FT-IR and XPS measurements revealed that inter- and intra-chain dehydration and chemical crosslinking (C-O ether linkage) occur on the surface of whitened PVA; thus, it seems that three-dimensional chemical networks associated with dehydration and crosslinking can be formed, and curing proceeds on the whitened PVA surface.

Moreover, the animal glue used as traditional binder of pigments in Japanese paintings may be the source of PVA cracking. The elasticity of animal glue can vary significantly with changing humidity. PVA was coated on a color layer that contains animal glue. Hence, we believe that wrinkles and cracks can be formed on the PVA surface easily by the difference in the elastic properties between cured PVA and animal glue on the color layer. As a result, cracks on the PVA surface cause refraction of light, which gives the appearance of whitening.

The information in this paper provides a basis on which to investigate how to remove whitened PVA from the surface of paintings without any damage.

\section{ACKNOWLEDGEMENTS}

This work was supported by a Grant-in-Aid for the Global COE Program by the Ministry of Education, Culture, Sports, Science and Technology. We appreciate the gift of polyvinyl alcohol from Kuraray, Japan.

1 Mogi, A. History and present results of preventive treatments against exfoliation of screen and panel paintings in Shoinzukuri type buildings. Sci. Conserv. 12, 49-54 (1974).

2 Iwasaki, Y. \& Nakasato, T. A list of preservative treatments with synthetic resins for the cultural property. Sci. Conserv. 13, 85-101 (1975).

3 Takenouchi, Y. \& Kawanobe, W. Survey of synthetic resins applied for the conservation of Japanese buildings. Sci. Conserv. 37, 99-123 (1998).

4 Kawanobe, W. in Senri Ethnological Reports 36; Synthetic Materials and the Museum Object (ed. Sonoda, N.) Ch. 2, 103-114 (National Museum of Ethnology, Osaka, Japan, 2003).

5 Kawanobe, W. Synthetic resin in restoration of cultural property. Polymers 56, 588-592 (2007).

6 Oka, I. in Senri Ethnological Reports 36; Synthetic Materials and the Museum Object (ed. Sonoda, N.) Ch. 2, 93-101 (National Museum of Ethnology, Osaka, Japan, 2003).

7 Carretti, E., Dei, L. \& Baglioni, P. Solubilization of acrylic and vinyl polymers in nanocontainer solutions. Application of microemulsions and micelles to cultural heritage conservation. Langmuir 19, 7867-7872 (2003).

8 Pouli, P., Nevin, A., Andreotti, A., Colombini, P., Georgiou, S. \& Fotakis, C. Laser assisted removal of synthetic painting-conservation materials using UV radiation of ns and fs pulse duration: morphological studies on model samples. Appl. Surface Sci. 255, 4955-4960 (2009)

9 Korodenko, G. D., Lipatov, Y. S., Fabulyak, F. G., Pugachevskii, G. F., Tuichiyev, Sh. \& Lukashov, V. S. Effect of sodium acetate on the structure of polyvinyl alcohol. Polym. Sc. U. S. S. R. 26, 280-286 (1984).

10 Aoki, H., Yoshida, A. \& Suzuki, T. The kinetic evaluation for photo-oxidation of PVA (polyvinyl alcohol). Soc. Mater. Sci., Jpn. 22, 48-56 (1973).

11 Tanaka, S., Naganuma, Y., Kato, C. \& Horie, K. Surface modification of vinyl polymers by vacuum ultraviolet light irradiation. J. Photopolym. Sc. Technol. 16, 165-170 (2003).

12 Tadokoro, $\mathrm{H}$. Infrared studies of polyvinyl alcohol by deuteration of its $\mathrm{OH}$ groups. Bull. Chem. Soc. Jpn. 32, 1252-1257 (1959).

13 Akhter, S., Allan, K., Buchanan, D., Cook, J. A., Campion, A. \& White, J. M. XPS and IR study of X-ray degradation of PVA polymer film. Appl. Surface Sci. 35, 241-258 (1988-89).

14 Grohens, Y., Auger, M., Prud'homme, R. \& Schultz, J. Adsorption of stereoregular poly (methyl methacrylates) on $\gamma$-alumina: spectroscopic analysis. J. Polym. Sci.: Part B: Polym. Phys. 37, 2985-2995 (1998).

15 Marupov, R., Kalontarov, I.Ya. \& Konovalova, G. I. Infrared spectra of dehydrated polyvinyl alcohol. J. Appl. Spectrosc. 8, 657-659 (1968).

16 Peng, Z. \& Kong, L. X. A thermal degradation mechanism of polyvinyl alcohol/silica nanocomposites. Polym. Degrad. Stab. 92, 1061-1071 (2007).

17 Kupčík, J., Blazevska-Gilev, J. \& Pola, J. IR laser-induced degradation of poly (vinyl acetate): novel thermal reactions in solid polymers. Macromol. Rapid Commun. 26, 386-389 (2005).

18 Kusunoki, K., Kawanobe, W. \& Hayakawa, N. Physical property of animal glue as restoration material. Bunkazai Hozon Shufuku Gakkaishi 51, 1-13 (2006).

19 Helfand, M. A., Mazzanti, J. B., Fone, M. \& Reamey, R. H. Effect of acetate distribution on surface segregation in poly(vinyl alcohol-co-vinyl acetate) copolymer films. Langmuir 12, 1296-1302 (1996). 